\title{
Citizen RElationship MANAgEMENT AND PRINCIPAL/AgENT THEORY
}

\author{
Ameneh Malmir*, Alireza Shirvani (Ph.D), Ali Rashidpour(Ph.D), Iraj \\ Soltani(Ph.D) \\ Department of management, Khorasgan(Isfahan) Branch, Islamic Azad University, Iran
}

\begin{abstract}
Principal/Agent Theory economic that makes clear accountability relationship management (Agent) to shareholders (Principal), Have the effect of creating new public management .This theory highlights important issues regarding the accountability of state structures that distinguishes private structures. This theory of public administration causes agents to act and be accountable to their citizens' interests. Although the Principal/Agent theory does not provide a complete solution for administration accountable, but accountability relationships which reveal a positive step in improving accountability. This theory is one of the factors citizen relationship management. In this article we will examine the relationship between Principal/Agent theory and citizen relationship management.
\end{abstract}

\section{KEYWORDS}

Citizen Relationship Management, Principal/Agent Theory, Clientele.

\section{Introduction}

Principal/Agent Theory or agency brokerage also applicable in the public sector and in terms of specificity, have been used to respond to it. This theory is designed to explain the difference in the private sector that often exists between the goals of shareholders (Agent) and management objectives (Principal) are the owners of the depositary. How the different interests of members and managers and how to deal with them is to provide a broad literature on accountability issues and adverse effects on organizations. Are shareholders want maximum profit, while managers may seek long-term growth and greater rights for themselves( Mostafaei, Mehran,1991). Institutions may not necessarily maximize profits for the benefit of shareholders; Shareholders because it reduces the power of the separation of ownership from control. Although it is not to maximize profit and share of stock, however, there must be some profit. Theory of incentive schemes aimed at providing a way for the agents to act in shareholders' interests. Activities are regulated and controlled by the agents of shareholders is possible that this activity can lead to confiscation or bankruptcy. Authentic and lawyers applying theory in the public sector will lead to a broken accountability system. Home owners who are hard to detect, and what their true desires. Government or the public sector can be considered the original owners. For agents, it is difficult for government managers who do know what they want from each of the owners in each case. Does not impact the profit motive, the stock market does not exist, and there is no measure of bankruptcy. If you owned the lack of adequate tools to ensure that they do not fulfill the demands of the agents, they probably do not give 
agents. In other words, if a private sector organization, there is a problem, it is more likely that the problem is more acute in the public sector.

\section{Theoretical literature and literature}

\section{Citizen Relationship Management}

Usually, the general understanding is that the public service does not meet the expectations of the people and governments at all levels, compared with the traditional attitude of the private sector are seen as backward. Government agencies dealing with clients in a way that people are treated as state prisoners, not only have the choice of, It can handle any kind of behavior. Meet the traditional ruler of the state is merely legal accountability, legal accountability is also associated with complications. Which may not be replaced by customer-oriented principles(Divandari Ali - optional, J,1993).

Compare the performance of government agencies with private organizations, they are evaluated. And the lack of appropriate performance, thus shattering the sense of pessimism and inefficient administrative system as follows. It is for this reason that governments, development and administrative reform as a reform movement consider and treat as a priority. But the raw action and diversity initiatives for administrative reform, no direction and no change in the philosophy of system administration, not only will a positive result, Rather than the performance of public officials and citizens will be pessimistic. Thus, the domination of traditional thinking, customer focus and become the customer-led government, consider the four principles of administrative system reform is necessary (Glenn Field, 2001).

Principles of administrative reform

To change the administrative system and hope for its success is essential to consider the following principles:

\section{Establish a clear national standards of public accountability:}

As long as the principle governing the public service that the government will accept the responsibility that all citizens have the right to receive high quality services. Also have the right to have access to proper standards and public services, If standards are not met, the facility will provide mechanisms for rights violation. Standards should be meaningful to the public, a clear and understandable and accessible to the people to pursue their rights expected to be institutionalized understanding, motivation, participation and obey their rules.

\section{Implementation of standards through delegating to the executive agencies and managers of local organizations:}

This principle will be applicable provided that governments and local organizations rely somewhat risky. Delegation is a tool that makes state of availability. Better service demand freedom and flexibility, administrators and staff of local organizations to get rid of unnecessary restrictions and controls. 


\section{Flexibility:}

Flexibility entails reducing bureaucratic boundaries and encouraging and rewarding employees, leadership and management demands of citizens diverse services.

\subsection{Reduction of bureaucratic boundaries and limit paperwork:}

Governments are often announced new rules to address operational issues without being eliminated or reduced the previous laws and guidelines. Admittedly rules play an important role in preventing fraud, embezzlement, abuse and corruption has set minimum standards, But freedom of creativity and innovation will be confronted with increasing regulation.

\subsection{Encouraging and rewarding employees:}

First line employees and government organizations to provide quality services to more responsibly and should be identified and receive appropriate rewards.

\subsection{Leadership and management of citizens' demands:}

The term public service and top quality service, support and improve the skills of their managers. So not only managers, but all brokers should be broadly trained in the skills and customer focus( Hassani, A,1994).

\section{Increasing options:}

Public service providers should have a chance to increase customer choice. Citizens have many different applications, and sometimes they ask for better service. They receive better services with less time and more speed, and also to pay the price for it. Services provided by different institutions, will provide the opportunity to compete and improve quality(Motevasseli, Mahmoud,1992).

\section{Philosophy of clients in government agencies}

Customer in 1980 under the banner of New Public Management was introduced in the public sector. Thus, according to the Government Accountability Social Development, governments were forced to respond to customers and to use information technology to set tasks. The incentives for government agencies to implement customer-oriented strategy is different and each with different goals, strategies they choose. Goals such as the development of operational efficiency, implementing performance based on strategic guidelines, refer to sources outside the organization, career-oriented, competition oriented reorganization of work processes based on customers' needs and so on. But government agencies are pursuing four major objectives in the customer-oriented.

1. Improve the effectiveness of public services

2. Improve internal efficiency

3. Improve the company's image with others

4. New challenges for brokers and public managers

Perhaps realizing the above objectives, the first factor, the effectiveness of the goals is difficult because the measurement of service quality improvement is possible with quantitative measures. 
In this regard, government organizations must do the following steps to measure the effectiveness of customer.

1. Tangible to work within the work unit

2. Measuring range of clients

3. Measuring value (value of bureaucratic)

4. The measurement results

\section{Government targets, customer-focused}

For policy makers, the customer is not always right customer. The objective of the government customer, identifying all stakeholders both internal and external and create and enhance communication with and taking into account the demands and in line with the requirements of appropriate role in resource allocation and potential and actual use in the country(Turner, Mark and David Hume, David,1998).

Customer relationship management between the public and private sectors often, the meaningful participation of citizens in political decision-making is participation in elections and referenda are usually reaches its peak ,but most people are not aware of their role in government organizations governmental organizations are not granted any right to them and the relationship between them is considered between them does not pose any balance; but it is quite clear that the balance of private and non-compliance with the conditions of the game, do not be exchanged. Thus, the public sector responsibilities and restrictions that are not in the private sector.

1. Customers of public choice to go elsewhere for the services they receive. Likened the situation to the client and the client is not correct. for example, when a client stands never feel a client is not a customs inspection.

2. Many government agencies, information from customers when they can not act on the basis of the authority of government officials is not solving the problems of the citizens depends to a higher authority(Heidarzadeh, Kambiz ,1990).

3. The concept of the citizen means knowing the client's failure to consider the role of citizens. The concept of citizenship regardless of its instances involving the whole population, but the essence of the concept of citizenship, volunteering and active participation of citizens in public affairs.

\section{Principal/Agent Theory In the study of organizations}

Political and economic actors are organizations of their ability to influence public opinion, electoral behavior and government policy places (Herman and Chomsky, 1998). Meanwhile, with the aim of "maximizing profits" are motivated. Classical theory - lawyer used to understand the behavior of individuals in organizations seeking to gain political organizations as well as individuals and legislative lawmakers. Applying the principles of agency theory framework, the behavior of individuals in different hierarchical levels of the organization, represent important variables affecting such cost monitoring, incentive and control mechanisms of virtual enterprise, which is mainly on enterprise content. Traditional approach - studying political organizations as well as legislative counsel and legislative conform. (Cults and Zpan, 1990, Joy 1987, Levin and 
Furness, 1990 and Vesylbrg Nilsson, 1987). Here the maximum amount of votes and other political and economic forms typically profit maximization is replaced with the best intentions.

\section{Agency theory}

Broad framework of institutional theory, agency theory, the name comes from. Jnsyn and Mac Ling (1976) definition of a genuine relationship - lawyers offer: The key point is that although traditional methods for controlling a Lawyer But without the supervision of a lawyer's behavior possibility for the lawyer to go there (Okin and Dmzbh, 1972, Perth and Zchhavsr, 1985). This scenario is often cited as Jnsyn and Mac ling time. Since this is due to the activity monitoring is costly. Overall, the biggest losses when the broker takes the values and interests differ considerably in their original lawyer or monitoring costs are too high. (Perth and Zychhavser, 1985)

\section{Types accountability}

\section{One. The traditional accountability}

From a legal point of view and may be considered in management. In terms of corporate accountability in the traditional model, a subordinate ruler asks the government. At best, you have to deal with a ruler pious and wise judgments according to reason that others will want to strive to provide the materials. But the point is that he is not answerable to think and act, and his command. From a managerial perspective approach to overcome the problems and responsibilities of the project is to create hierarchical structure accountability to Max Weber Hughes, Aven,1999). The system of public administration requires a clear separation between those who give orders and those who carry out the orders and is not responsible for the results. The traditional pattern of hierarchical structure has relied on informal communications. Bureaucratic accountability usually means responding to the political leadership and the politicians accountable to others. This is not intended as a way for the administration to respond directly related citizen.

However, for the reduction of errors and pitfalls to be avoided and there should be institutionalized to ensure accountability of law( Napoli, P.M,1997).

\section{Two. New accountability}

In the new model, the relationship between the administrative system instead of the politicians is to establish a direct connection. This model has two basic assumptions of human beings exposed to the possibility of human error and corruption.

Is the act of responding to the individual or individuals responsible for duties or In other words, the reason why they want things done and undone tasks is intended that the principles governing:

- Client's Rights

- There is a clear definition of the responsibilities of the enclosure

- Being responsible for specific work

- Assigning accountability for the duties of an 
- documented and reasoned responses

- Goals and Results

- To ensure proper performance and compliance with program

- Correction of errors

- Identifying weaknesses prevent their recurrence

- influence on behavior

- effective use of physical resources, financial and human resources to gain maximum efficiency.

- Maintaining morale of workers with their efforts to inform others and to cherish them.

- To obtain the most advantageous economic resources

- To prevent abuse, intentional or unintentional use of resources

- Provide timely salary and benefits

- increase the effectiveness of work done

- Customer satisfaction per unit

- proper implementation of laws and regulations( alvani, danaie fard,1999)

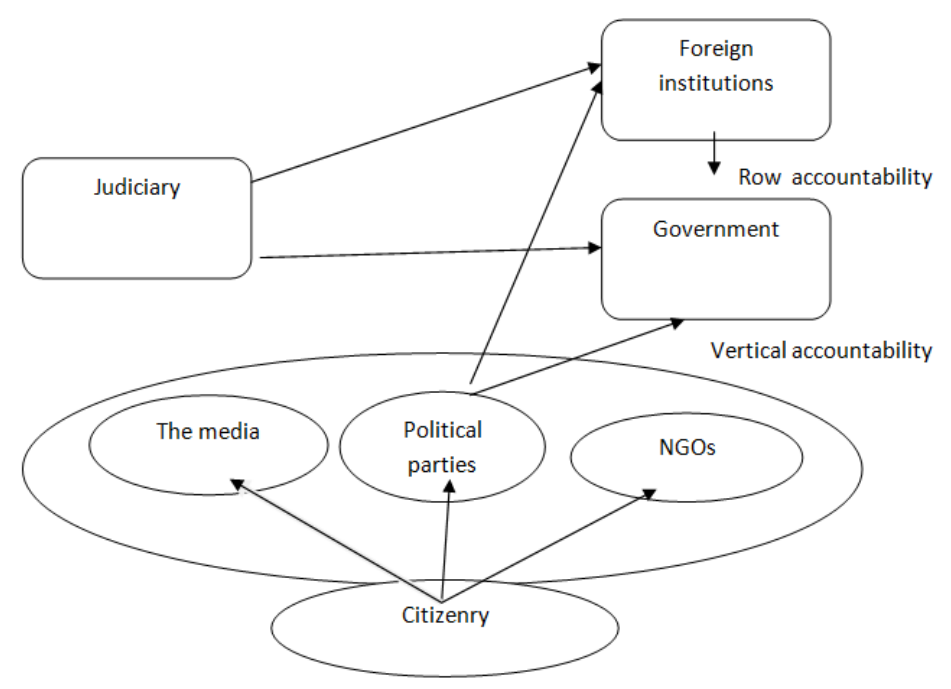

Figure 1: The institutions of accountability (UNDP, 2004)

Reasons of lack of transparency and accountability in IRAN

Many reasons can be mentioned about the lack transparency and accountability in, but what follows is due to the cultural and social characteristics of a particular matter. A few examples are mentioned in this context is an essential and effective:

\section{Relative orientation}

One of the distinguishing features family-oriented culture in the history of Iran. This phenomenon has resulted in the administrative system of meritocracy is threatened. Primarily in countries that have strong family ties and other relationships requires that person to your family and friends for help. It will be difficult to establish the ideal type of bureaucracy (Weberian)( ZABIHi, M,1996). 


\section{2- Lack of legality}

With all the respect and attention that is required by law and is necessary in all societies, but few problems credit and lack of proper implementation and complete rules, more or less there. although national laws and regulations and have complied fully, the issue of legality is not an issue that can be caused by the following constraints:

\section{(A) Cultural barriers}

Lack of institutionalized culture of accountability, serious and strong hierarchical structure which died not long answer is self subordinates.

\section{(B) Social barriers}

These barriers include lack of compliance with the conditions and unfamiliarity with the rules and regulations of the elements in the structure (in terms of multiplicity, contradiction and ambiguity in them).

\section{(C) Administrative system}

In the past, the administrative system composed of respondents who could not deal with complaints and to impose the appropriate punishment and reward work( Mirsepasi, N.; Bagherzadeh, MR,1994).

\section{Conclusions}

In general, the response can be analyzed in two dimensions is: After the first response personnel and employees of the local stakeholders (organizational hierarchy) and then respond to other versus external stakeholders (clients / customers). Therefore, the response time can be implemented very reasonable external stakeholders that firstly, organizations and the general state accountability system have been properly inside their premises, thereby providing the means to respond. Secondly, in order to move to keep pace with the international community and take action to implement the relevant standards. Public choice theory and original and lawyers have created a rational relation to the reduction of government services and the management re-structuring. In addition, many have questioned the concept of public administration, such as lifetime employment, promotion based on seniority, under government employment, the traditional answer, even bureaucratic theory due to the lack of a strong theoretical basis and incompetence in creating adequate incentives for performance fine. For example, one of the main shareholders are the citizens through elections to choose a lawyer to protect the interests of citizens and stakeholders (citizens) to create and promote the welfare and prosperity to their town. If the lawyer's fiduciary duty to the people, value creation, development and prosperity do not act with imprudence, inefficient threaten the interests of shareholders. Shareholders will have no choice but to dismiss their responsibilities. Citizens who pay taxes and a variety of direct and indirect effects are involved in managing a city have the right to ask their lawyers navigate the resources, create maximum benefits for them. Can be Seen some councils and executive bodies unprofessional decisions and investment interests of shareholders and citizens risked their losses and create, the municipality and its citizens risked squandering of resources, opportunities to fire. The real truth is that citizens are concerned about their 
environment and the need to have peace of mind. Because when they hear the news as evidence that the abuse of the trust must take refuge in how the mechanism for removal of this group of people, there is another advantage. Perhaps one of the problems in our country endured four years to revise the electoral law further selection lawyers.

\section{References}

1. alvani, danaie fard. (1999). "Public Administration and the Public Trust, Knowledge Management, No. 55, Tehran University Press.

2. Divandari Ali - optional, J. (1993) developed a model designed to measure customer satisfaction in the banking industry and bank based on the measurement of customer satisfaction, Journal of Business Research, No. 37.

3. Hassani, A. (1994), "Effects of organizational citizenship behavior on customer perception of service quality, customer satisfaction and behavioral intentions", Faculty of Management, Tehran University, Master Thesis.

4. Heidarzadeh, Kambiz (1990) Marketing management pathology. Tact, No. 125.

5. Hughes, Aven. (1999). Translation, alvani, Schwerin and Memarzade, "new public management", publisher pearls, third edition.

6. Management and Planning Organization. (1990). "Reports the country's administrative system reform plan", Tehran: Department of Management and Human Resources.

7. Mostafaei, Mehran. (1991). "The role of political system reform", Journal of the seventeenth of April.

8. Motevasseli, Mahmoud. (1992). "Optimal combination of privatization and economic development of the state and the market," Trade Studies and Research Press.

9. Mirsepasi, N.; Bagherzadeh, MR. (1994). "Pathology accountability systems in public organizations", Research Journal - overall management of the third year, No. 712.

10. Napoli, P.M. (1997). A Principal-Agent Approach to the Study of Media Organization: Toward Theory of the Media Firm, Political Communication, No14 .

11. Turner, Mark and David Hume, David. (1998). Translation: Monavaryan, A., "Governance and Development Management", published by the Center for Public Management Education.

12. ZABIHi, M. (1996). "Effect of service quality on customer satisfaction: (case study of four-star city hotel", Master Thesis in Business Administration - Finance Administrative Sciences and Economics University. 